\title{
Access to Essential Medicines in Ghana: A Survey of Availability of Children's Medicines in Medicine Outlets in the Ashanti Region
}

\author{
Grace Frimpong ${ }^{1,2}$, Kwabena Ofori-Kwakye ${ }^{1^{*}}$ \\ ${ }^{1}$ Department of Pharmaceutics, Faculty of Pharmacy and Pharmaceutical Sciences, College of Health Sciences, Kwame Nkrumah University of Science and \\ Technology, Kumasi, Ghana. ${ }^{2}$ Department of Pharmaceutical Sciences, Faculty of Medicine and Health Sciences, Kumasi Polytechnic, Kumasi, Ghana.
}

\begin{tabular}{l} 
ARTICLE INFO \\
\hline Article history: \\
Received on: 08/06/2016 \\
Revised on: 04/07/2016 \\
Accepted on: 10/08/2016 \\
Available online: $29 / 10 / 2016$ \\
\hline Key words: \\
Children's medicine, \\
medicine outlets, essential \\
medicines, paediatric \\
medicine, stock-outs.
\end{tabular}

\begin{abstract}
The objective of this study was to assess the availability of 42 children's essential medicines contained in the Standard Treatment Guidelines (STG) of Ghana in the 27 districts of Ashanti Region. Five hundred medicine outlets comprising of hospitals/health centers/clinics, community pharmacies and chemical shops were surveyed using a validated structured questionnaire. The results were analysed and the availability of the 42 medicines in each district was determined. The average availability of children's medicines across the region was $41.3 \%$ (range: 26.4-52\%), with the Kumasi Metropolis (KM) and Bosome Freho (BF) district having the highest and lowest availabilities, respectively. Six $(14.3 \%)$ of the medicines, omeprazole, tinidazole, furosemide and spironolactone suspensions, and praziquantel and thiabendazole syrups had zero availability in the Region while ferrous sulphate syrup (95\%), albendazole suspension (90\%) and paracetamol syrup (88.8\%) had the highest availabilities. Three hundred and twenty three different formulations of the 42 medicines were identified with foreign and local manufacturers accounting for $198(61.3 \%)$ and $125(38.7 \%)$ formulations, respectively. India $(38.7 \%)$ and United Kingdom $(35.5 \%)$ were the major foreign manufacturers. The duration of stock-outs was shorter for private than public/government facilities and generally ranged from up to one week $(68.4 \%)$ to over one month $(3 \%)$. Reasons for the low or non-availability of children's medicines included the lack of funds, non-prescription by physicians, unavailability of medicines at wholesalers and lack of awareness of medicine outlets staff.
\end{abstract}

\section{INTRODUCTION}

The Ministry of Health, Ghana in 1983 introduced the Essential Drugs List (EDL) to help to rationalize medicines use in the country (MOH, 1993). In 1988, the first edition of the Standard Treatment Guidelines (STG), a sequel to the EDL, was published by the Ghana National Drugs Programme (GNDP), an affiliate of the Ministry of Health, Ghana. The STG is aimed at all levels of healthcare, both public and private, and is meant to assist healthcare professionals in their treatment choices $(\mathrm{MOH}$, 2010). It is also intended to provide quality standardized care at affordable cost, and to ensure that quality essential medicines for adults and children are available at hospitals, clinics, pharmacies and other medicines outlets throughout the country at the right time. The STG currently contains several children's essential

\footnotetext{
* Corresponding Author

Kwabena Ofori-Kwakye

Emai:koforikwakye@yahoo.com
}

medicines which covers disease conditions of children as diverse as gastrointestinal disorders, pneumonia, malaria and otitis media. Children's medicines are medications specifically formulated and manufactured for use by children usually from the age of 0 to 12 years. The need for adequate children's medicines supply for the provision and expansion of healthcare delivery for children cannot be over-emphasized.

The European Union, recognizing the need for better medicines for children enacted the Paediatric Regulation on $26^{\text {th }}$ January 2007 to improve the health of children in Europe by facilitating the development and availability of medicines for children aged 0 to 17 years (EMA, 2015; Olski et al., 2011). Also, the International Pharmaceutical Federation (FIP) and the International Federation of Pharmaceutical Manufacturers \& Associations (IFPMA) have undertaken to work in tandem with the WHO and other stakeholders to develop and increase the availability of safe and effective child-specific medicines and child-appropriate formulations (FIP, 2008; IFPMA, 2015). 
The improvement in child survival and care for children affected by major diseases are global priorities included in the Millennium Development Goal 4 (MDG4) - to reduce child mortality, and 6 (MDG6) - to fight HIV/AIDS, malaria and other major childhood diseases (UN, 2010). The need for better access to appropriate essential medicines for children is well documented and recognized as an integral element to achieving development goals (Hoppu and SriRanganathan, 2015). The credibility of health authorities and the morale of health workers at all levels are seriously challenged when health facilities are unable to provide patients with the necessary good quality medicines (Finney, 2011).

The lack of availability and poor quality of children's medicines may arise from over-emphasis on accessing adult medicines, children's medicines losing their potency while awaiting port clearance due to bureaucratic inefficiencies, and children's medicines reaching their expiry dates at the warehouses because of poor planning and distribution ( $\mathrm{MOH}, 2010)$. Barriers to access and use may also include lack of information, lack of appropriate dosage forms, and pricing and supply system challenges (Finney, 2011). The limited availability of medicines registered for the use of children has been cited as the main barrier to the accessibility of safe and effective medicines for children in the Commonwealth countries (Ojoo, 2015).

The poor availability of medicines for children has been reported extensively in the literature. In Ghana, the Ecumenical Pharmaceutical Network (EPN) conducted a study to assess the availability and factors which affect access of essential medicines for children in 45 (37\%) Christian health facilities under the Christian Health Association of Ghana (CHAG) in the ten regions of Ghana (EPN, 2011). The survey which covered 15 medicines in 6 formulations found an overall availability of the children's medicines in church health institutions to be $67 \%$. A WHO survey of children's medicines availability in 14 African countries also revealed poor availability of medicines for children in both public and private health facilities (Robertson et al., 2009). A study to assess the prices and availability of children's essential medicines in Shaanxi Province, China found the mean availabilities of originator brands and lowest-priced generics to be $10.8 \%$ and $27.3 \%$ in public hospitals and $11.9 \%$ and $20.6 \%$ in private pharmacies (Wang et al., 2014). A study in Australia found that even though there had been improvements in medicines licensed for older children there was no improvement for children under the age of two years (Chui et al., 2004). A cross-sectional study in a pharmacy and children's department at a tertiary care hospital in India found that only $55.8 \%$ of 258 children's medicines were available and a gross deficiency of child-specific children's formulations was also observed (Desai et al., 2012). A national survey on the availability of key children's essential medicines in Sri Lanka obtained mean availabilities of 52\% (public hospitals), $80 \%$ (private hospitals) and $88 \%$ (ROS pharmacies) (Balasubramaniam et al., 2011). A study in the Netherlands on the availability and age-appropriateness of medicines authorized for children found that the appropriateness of the children's medicines with respect to their authorization status, dose capability and dosage form increased with age from 27-88\%. The study confirmed that there was limited availability of children's medicines for a broad range of therapeutic areas and that some authorized drugs may not be age-appropriate (van Riet-Nales et al., 2011).

The objective of the current study was to ascertain the availability of 42 children's essential medicines contained in the STG of Ghana at facility levels in the 27 districts of the Ashanti Region, Ghana. The results of this study will be helpful in informing policy makers on the acquisition and effective distribution of essential children's medicines in Ghana. It will also go a long way to improve access of essential medicines to children who form a significant proportion of the vulnerable population in the country.

\section{METHODOLOGY}

\section{The Study Area}

This study was undertaken in the Ashanti Region of Ghana. The Ashanti Region (Capital: Kumasi) has 27 districts and is the third largest of the ten administrative regions in Ghana. The Ashanti Region was selected for the study because it is the most populous region in Ghana with a population of 4,780,380 (2010 census). Additionally, the region has a high number of medicine outlets including 86 hospitals/health centers/clinics, 410 pharmacies and 1745 licensed chemical shops. The Kumasi Metropolis is the most populous of all the districts in Ashanti, with about $42.6 \%$ of the total population of the region (GSS, 2012; $\mathrm{MOH}, 2006)$. Figure 1 is a map of Ashanti Region showing all the 27 administrative districts.

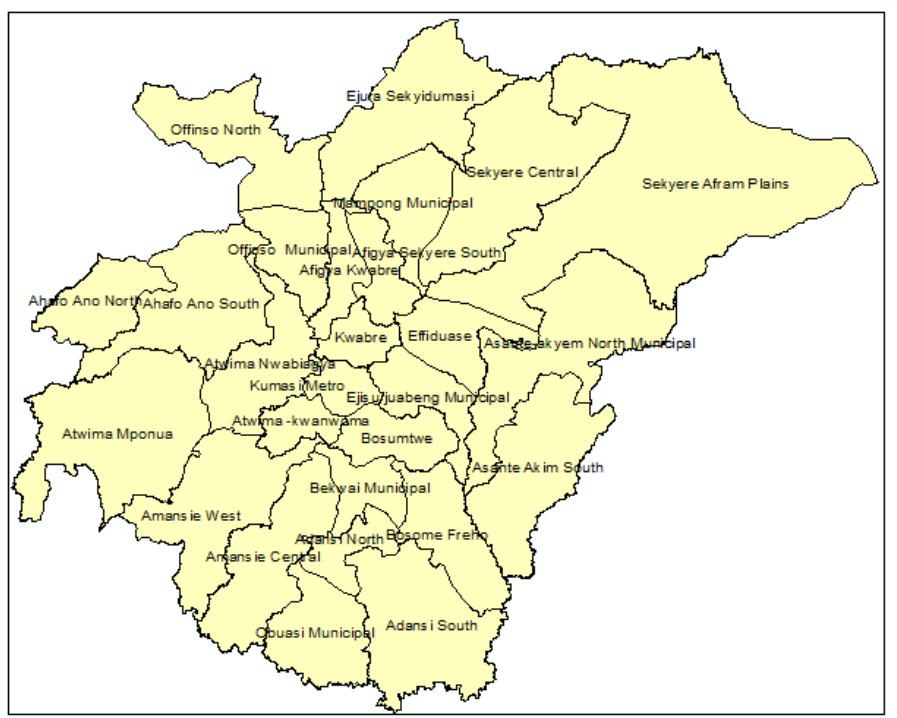

Fig. 1: A map of Ashanti Region, Ghana, showing the 27 administrative districts. Source: Google images

\section{The study facilities}

The survey was undertaken in medicine outlets in the 27 districts of the Ashanti Region. The medicine outlets comprises of 
hospitals/clinics (public and private), community pharmacies and chemical shops. Community pharmacies are registered retail medicine outlets legalized to supply prescription and nonprescription medicines and are engaged in the management and treatment of minor diseases in the community. Community pharmacies are superintended by professional pharmacists. Chemical shops are registered to supply over-the-counter (OTC) medicines used in the treatment of common diseases in communities which are without community or hospital pharmacies and are mostly managed by non-professionals. Hospitals (government, private or faith-based) are large health facilities engaged in secondary and tertiary care services. Hospitals have their own pharmacies (managed by pharmacists) where medicines are supplied to both in-patients and out-patients. Clinics are small health facilities that provides primary care services and usually have small medicine outlets (mostly managed by non-pharmacists) for the supply of medicines to clients.

\section{Sampling of Medicine Outlets}

Ethical clearance was sought from the Committee on Human Research and Publication Ethics (CHRPE) at the School of Medical Sciences, Kwame Nkrumah University of Science and Technology (KNUST), Kumasi. Official permission for the study was also sought from the Ashanti Regional manager of the Pharmacy Council, Ghana, as well as from medical administrators, superintendent pharmacists and proprietors/managers of the selected hospitals, clinics, pharmacies and chemical shops in all the districts in the Ashanti Region. A list of children's essential medicines covering broad therapeutic areas of common children's diseases in Ghana was compiled from the current edition $\left(2010,6^{\text {th }}\right.$ edition) of the Standard Treatment Guidelines, published by the Ministry of Health, Ghana. A list of registered hospitals and clinics, including government, private and mission or faith-based hospitals in the Ashanti Region was obtained from the Ashanti Regional Health Directorate, Kumasi, Ghana. Additionally, a list of registered pharmacies (wholesale and retail) and licensed chemical shops in the Ashanti Region was obtained from the office of the Regional Manager, Pharmacy Council, Kumasi. A total of 2,241 registered medicines outlets were obtained using the list from the Pharmacy Council zonal office. Random sampling was employed to select 500 medicine outlets to be surveyed for the availability of paediatric medicines and stratified sampling was used to apportion the number of medicine outlets to be surveyed in each district. By the use of stratified sampling, 18 medicine outlets were apportioned to each district, except the Kumasi Metropolis (40 medicine outlets) and Bosome Freho (10 medicine outlets) district. The Kumasi Metropolis was most well-endowed with several medicine outlets whereas Bosome Freho was the least endowed, with only 10 chemical shops and without a community pharmacy or hospital/clinic.

Five hundred structured pre-validated questionnaires containing open and close-ended questions were prepared and used in collecting information on the availability of children's medicines from the 500 randomly selected medicine outlets. The objectives of the study were explained to the respondents and informed consent were sought before the questionnaires were administered. Face to face interviews were conducted with respondents in a private area within the medicine outlets/health facilities and the questionnaires used were anonymous to protect the identity of the respondents. The face-to-face interviews were held with facility managers/in-charges during the survey period (June-August 2014). The researcher filled the questionnaires according to the information obtained from the respondents. Children's formulations of the selected medicines available in the facilities were physically inspected to ascertain relevant information such as brand name, manufacturer, etc. The percentage availability of children's medicine was calculated as follows:

$\%$ availability $=$ [number of medicine outlets stocking product/number of medicine outlets surveyed] x 100

A children's medicine was deemed to be available if at least one brand and/or generic product of the listed medicine was found in a medicine outlet or facility. Other information collected from the survey were the sources of medicines supply, available formulations, local/foreign manufacturers, duration of stock-outs, frequency of supply and reasons for non-stocking of specific children's medicines.

\section{Analysis of Data}

The information obtained from the survey was edited, coded and entered into the Statistical Package for Social Science (SPSS) software, version 16, and analyzed. The descriptive data was presented as frequencies and percentages.

\section{RESULTS}

A total of five hundred structured questionnaires were successfully completed through face to face interviews with respondents in the five hundred medicines outlets selected. The response rate was therefore $100 \%$. The professions/qualifications of the respondents were as follows: $104(20.8 \%)$ pharmacists, 19 (3.8\%) medical officers/physician assistants, 65 (13.0\%) dispensing technologists, 150 (30.0\%) medicine counter assistants, $22(4.4 \%)$ nurses/midwives and 140 (28.0\%) GCE 'O' level/SSCE/WASSCE/MSLC holders (no formal training in health/medicines). The sex of the respondents comprised of 284 $(56.8 \%)$ males and $216(43.2 \%)$ females. The age profile of the respondents was as follows: 20-25: $10(2 \%), 26-30$ : $157(31.4 \%)$, 31-40: 145 (29.0\%), 41-50: 96 (19.2\%), 51-60: 70 (14.0\%), and above 60: $22(4.4 \%)$. Table 1 presents the distribution of medicine outlets sampled and the average percentage availabilities of the forty two children's essential medicines in the 27 districts of Ashanti Region. Five hundred medicine outlets were successfully surveyed. The average availability of the children's medicines in the 27 districts was $41.3 \pm 6.0 \%$ (range: 26.4-52.0\%). The Kumasi Metropolis (KM) and Bososme Freho (BF) had the highest and lowest availabilities, respectively. 
Table 1: Availability of children's medicines in medicine outlets surveyed in the 27 districts of Ashanti Region, Ghana.

\begin{tabular}{|c|c|c|c|c|c|}
\hline District & Code & $\begin{array}{l}\text { Number of medicine } \\
\text { outlets sampled }\end{array}$ & $\begin{array}{l}\text { Children's medicines } \\
\text { surveyed }\end{array}$ & $\begin{array}{l}\text { Children's medicines with zero } \\
\text { availability, } n(\%)\end{array}$ & $\begin{array}{l}\text { *Availability of children's } \\
\text { medicines surveyed, \% }\end{array}$ \\
\hline Adansi North & AND & 18 & 42 & $8(19.0)$ & $37.8 \pm 29.8$ \\
\hline Adansi South & ADS & 18 & 42 & $9(21.4)$ & $41.3 \pm 31.8$ \\
\hline Afigya Kwabre & $\mathrm{AK}$ & 18 & 42 & $8(19.0)$ & $47.4 \pm 32.8$ \\
\hline Ahafo Ano North & AAN & 18 & 42 & $10(23.8)$ & $37.0 \pm 31.1$ \\
\hline Ahafo Ano South & AAS & 18 & 42 & $10(23.8)$ & $34.9 \pm 33.4$ \\
\hline Amansie Central & $\mathrm{AC}$ & 18 & 42 & $12(28.6)$ & $37.6 \pm 33.3$ \\
\hline Amansie West & $\mathrm{AW}$ & 18 & 42 & $10(23.8)$ & $40.6 \pm 33.1$ \\
\hline Asante Akim North & $\mathrm{AKN}$ & 18 & 42 & $9(21.4)$ & $47.8 \pm 36.2$ \\
\hline Asante Akim South & AKS & 18 & 42 & $10(23.8)$ & $45.3 \pm 35.6$ \\
\hline Atwima Kwanwoma & $\mathrm{AK}$ & 18 & 42 & $8(19.0)$ & $46.5 \pm 32.7$ \\
\hline Atwima Mponua & $\mathrm{AM}$ & 18 & 42 & $10(23.8)$ & $36.1 \pm 30.6$ \\
\hline Atwima Nwabiagya & AN & 18 & 42 & $8(19.0)$ & $46.6 \pm 37.1$ \\
\hline Bekwai Municipal & BM & 18 & 42 & $7(16.7)$ & $45.9 \pm 32.9$ \\
\hline Bosome Freho & $\mathrm{BF}$ & 10 & 42 & $17(40.5)$ & $26.4 \pm 28.3$ \\
\hline Bosomtwe & BT & 18 & 42 & $7(16.7)$ & $49.6 \pm 33.5$ \\
\hline Ejisu-Juaben & EJ & 18 & 42 & $10(23.8)$ & $41.0 \pm 36.3$ \\
\hline Ejura Sekyedumasi & ES & 18 & 42 & $8(19.0)$ & $37.7 \pm 33.2$ \\
\hline Kumasi Metropolis & KM & 40 & 42 & $6(14.3)$ & $52.0 \pm 34.0$ \\
\hline Kwabre & $\mathrm{KB}$ & 18 & 42 & $8(19.0)$ & $44.3 \pm 30.2$ \\
\hline Mampong Municipal & MM & 18 & 42 & $8(19.0)$ & $42.9 \pm 35.1$ \\
\hline Obuasi & OB & 18 & 42 & $8(19.0)$ & $45.6 \pm 33.0$ \\
\hline Offinso Municipal & OM & 18 & 42 & $7(16.7)$ & $49.3 \pm 34.6$ \\
\hline Offinso North & $\mathrm{ON}$ & 18 & 42 & $14(33.3)$ & $34.1 \pm 36.5$ \\
\hline Sekyere Afram Plains & SAP & 18 & 42 & $12(28.6)$ & $32.3 \pm 30.9$ \\
\hline Sekyere Central & $\mathrm{SC}$ & 18 & 42 & $9(21.4)$ & $39.4 \pm 33.2$ \\
\hline Sekyere East & SE & 18 & 42 & $8(19.0)$ & $42.3 \pm 31.4$ \\
\hline Sekyere South & SS & 18 & 42 & $9(21.4)$ & $39.5 \pm 32.8$ \\
\hline
\end{tabular}

*Mean availability of children's medicines in medicine outlets in all the 27 districts (Ashanti Region) was $41.3 \pm 6.0 \%$.

Table 2: Availability of children's antimalarial drugs, antibiotics and analgesics in medicine outlets in the 27 districts of Ashanti Region, Ghana.

\begin{tabular}{|c|c|c|c|c|}
\hline$\overline{\text { Drug }}$ & $\begin{array}{l}\text { *Formulations of } \\
\text { medicines available }\end{array}$ & $\begin{array}{l}\text { District with lowest } \\
\text { availability (District, \%) }\end{array}$ & $\begin{array}{l}\text { District with highest availability } \\
\text { (District, \%) }\end{array}$ & $\begin{array}{l}\text { Average availability } \\
(\%), n=27\end{array}$ \\
\hline \multicolumn{5}{|l|}{ Antimalarials } \\
\hline Artesunate-amodiaquine & $4(1)$ & $\mathrm{BF}(11.0)$ & ADS, AK (55.5) & $33.50 \pm 13.40$ \\
\hline Artemether-lumefantrine & 11(3) & $\mathrm{ON}(38.8)$ & $\mathrm{AKN}(100)$ & $72.80 \pm 12.70$ \\
\hline Dihydroartemisinin-piperaquine & $1(0)$ & $\mathrm{BF}, \mathrm{EJ}(0.0)$ & $\mathrm{KM}(55.5)$ & $32.60 \pm 17.40$ \\
\hline \multicolumn{5}{|l|}{ Antibiotics } \\
\hline Ciprofloxacin & $2(0)$ & $\mathrm{BF}, \mathrm{ON}, \mathrm{SC}(0.0)$ & AK (38.8) & $17.00 \pm 8.90$ \\
\hline Co-trimoxazole & $11(7)$ & $\mathrm{BF}(50.0)$ & AKS (100.0) & $77.50 \pm 11.13$ \\
\hline Metronidazole & $16(4)$ & ON (38.8) & OM, AK, EJ, ES (94.4) & $80.40 \pm 22.40$ \\
\hline Erythromycin & $3(3)$ & $\mathrm{ON}(11.1)$ & BT, AN (83.3) & $43.50 \pm 12.40$ \\
\hline Amoxicillin & $11(5)$ & $\mathrm{ON}(38.8)$ & AKS, EJ (100.0) & $76.40 \pm 11.70$ \\
\hline Azithromycin & $9(0)$ & $\mathrm{BF}(0.0)$ & $\mathrm{AN}(50.0)$ & $43.80 \pm 17.30$ \\
\hline Co-amoxiclav & $11(0)$ & $\mathrm{BF}(11.1)$ & $\mathrm{EJ}(72.2)$ & $50.60 \pm 11.70$ \\
\hline Clindamycin & $1(0)$ & $\mathrm{ON}(0)$ & $\mathrm{OB}(38.8)$ & $18.40 \pm 8.60$ \\
\hline Flucloxacillin & $8(5)$ & $\mathrm{ON}(27.7)$ & $\mathrm{KM}(90.2)$ & $68.70 \pm 11.0$ \\
\hline Cefuroxime & $15(3)$ & $\mathrm{BF}, \mathrm{AC}(0.0)$ & $\mathrm{KM}(70.7)$ & $36.00 \pm 13.80$ \\
\hline \multicolumn{5}{|l|}{ Analgesics } \\
\hline Ibuprofen & $15(6)$ & $\mathrm{BF}(50.0)$ & ON (88.8) & $71.50 \pm 6.60$ \\
\hline Paracetamol & $22(15)$ & $\mathrm{BF}(66.6)$ & $\mathrm{AKN}, \mathrm{AN}, \mathrm{OB}, \mathrm{ON}(100.0)$ & $88.80 \pm 7.30$ \\
\hline
\end{tabular}

*The number in parenthesis is the number of formulations of the various medicines manufactured locally in Ghana.

Only KM had a percentage children's medicines availability of $>50.0 \%$. The number of children's medicines which were not available in the districts ranged from six $(14.3 \%$, $\mathrm{KM})$ to seventeen $(40.5 \%, \mathrm{BF})$. Six $(14.3 \%)$ of the medicines, namely: omeprazole, tinidazole, furosemide and spironolactone suspensions, and praziquantel and thiabendazole syrups were unavailable (zero availability) in all the medicine outlets in the 27 districts surveyed. Tables 2, 3 and 4 show the average percentage availability of various therapeutic groups of children's essential medicines in the 27 districts of Ashanti Region, Ghana.
Artemether-lumefantrine suspension (mean: $72.8 \%$, range: $38.8-$ $100 \%$ ), metronidazole suspension (mean $80.4 \%$, range 38.8-94.4 $\%$ ) and paracetamol syrup (mean: $88.8 \%$, range: 66.6-100 \%) were the most prevalent antimalarial, antibacterial and analgesic medicines, respectively (Table 2). Most of the brands of antimalarials, antibiotics and analgesic medicines were manufactured by foreign pharmaceutical companies. Ferrous sulphate syrup was the most available children's haematinic medicine with an average availability of $95.0 \%$ (range: 72.2$100.0 \%$ ) (Table 3). 
Table 3: Availability of children's haematinics and antiepileptic drugs in medicine outlets in the 27 districts of Ashanti Region, Ghana.

\begin{tabular}{|c|c|c|c|c|}
\hline Drug & $\begin{array}{l}\text { *Formulations } \\
\text { of medicines } \\
\text { available }\end{array}$ & $\begin{array}{l}\text { District with lowest availability } \\
\text { (District, \%) }\end{array}$ & $\begin{array}{l}\text { District with highest } \\
\text { availability } \\
\text { (District, \%) }\end{array}$ & $\begin{array}{l}\text { Average availability } \\
\quad(\%), n=27\end{array}$ \\
\hline \multicolumn{5}{|l|}{ Haematinics } \\
\hline Zinc supplementation & $1(1)$ & SS, EJ (22.2) & ON (100.0) & $58.0 \pm 14.10$ \\
\hline Vitamin B complex & $11(11)$ & $\operatorname{AAS}(50.5)$ & ON $(94.4)$ & $74.40 \pm 8.85$ \\
\hline Ferrous sulphate & $45(11)$ & SAP (72.2) & $\begin{array}{l}\text { AK, AKN, AKS, AN, BM, BT, } \\
\text { EJ, MM, OB, OM, SC (100.0) }\end{array}$ & $95.0 \pm 4.30$ \\
\hline Ferrous fumarate & $1(0)$ & $\begin{array}{l}\text { ADN, ADS, AAN, AAS, AC, AW, AKN, AKS, } \\
\text { AK, AM, AN, BF, ES, KB, MM, OB, OM, ON, } \\
\text { SAP, SC, SE, SS (0.0) }\end{array}$ & $\mathrm{BM}(8.5)$ & $0.8 \pm 1.80$ \\
\hline $\begin{array}{l}\text { Ferrous Ammonium Citrate } \\
\text { (FAC) }\end{array}$ & $3(3)$ & $\mathrm{ADN}(5.5)$ & BT (83.3) & $51.0 \pm 16.90$ \\
\hline Folic acid & $1(1)$ & AN (5.5) & ON (66.6) & $31.60 \pm 15.60$ \\
\hline Multivitamin & $30(9)$ & AAN, AAS, BF, ES (72.2) & $\begin{array}{l}\text { AKN, AKS, AN, EJ, ON, SS } \\
(100)\end{array}$ & $87.50 \pm 8.50$ \\
\hline \multicolumn{5}{|l|}{ Anti-epileptics } \\
\hline Phenobarbitone & $3(3)$ & $\begin{array}{l}\text { ADS, AK,AAN, AAS, AC, AW, AKN, AKS, } \\
\text { AM, BF, EJ, ON, SAP, SS (0.0) }\end{array}$ & SE (27.7) & $4.40 \pm 5.30$ \\
\hline Phenytoin & $1(0)$ & $\begin{array}{l}\text { AND, ADS, AK, AAN, AAS, AC, AW, AKN, } \\
\text { AKS, AK, AM, AN, BM, BF, BT, EJ, ES, KB, } \\
\text { MM, OB, ON, SAP, SC, SE, SS (0.0) }\end{array}$ & $\mathrm{OM}(5.5)$ & $0.40 \pm 0.70$ \\
\hline
\end{tabular}

Table 4: Availability of antihistamines, anthelminthic drugs and other children's medicines in medicine outlets in the 27 districts of Ashanti Region, Ghana.

\begin{tabular}{|c|c|c|c|c|}
\hline Drug & $\begin{array}{l}\text { *Formulations of } \\
\text { medicines available }\end{array}$ & $\begin{array}{c}\text { District with lowest availability } \\
\text { (District, \%) }\end{array}$ & $\begin{array}{c}\text { District with highest availability } \\
\text { (District, \%) }\end{array}$ & $\begin{array}{c}\text { Average availability } \\
(\%), \mathrm{n}=\mathbf{2 7}\end{array}$ \\
\hline \multicolumn{5}{|l|}{ Antihistamines } \\
\hline Promethazine & $7(7)$ & AAN, AAS, AW, MM (27.7) & BT (77.7) & $49.0 \pm 14.50$ \\
\hline Cetirizine & $7(5)$ & SS (33.3) & KM, MM (90.2) & $83.0 \pm 15.70$ \\
\hline Chlorpheniramine & $6(1)$ & $\mathrm{BF}, \mathrm{ON}, \mathrm{SAP}(0.0)$ & $\mathrm{AK}(33.3)$ & $13.0 \pm 7.30$ \\
\hline \multicolumn{5}{|l|}{ Anthelminthics } \\
\hline Mebendazole & $10(5)$ & ON (38.8) & AK, AAS, AN, MM (83.3) & $62.70 \pm 9.6$ \\
\hline Albendazole & $20(5)$ & $\mathrm{BF}(61.1)$ & ON $(100.0)$ & $90.0 \pm 4.6$ \\
\hline \multicolumn{5}{|l|}{ Other medicines } \\
\hline Liquid paraffin & $1(0)$ & $\mathrm{AC}, \mathrm{AM}, \mathrm{BF}, \mathrm{SAP}(0.0)$ & AKN, BT, AW (55.5) & $24.0 \pm 15.30$ \\
\hline Saline nasal drops & $8(4)$ & $\mathrm{ON}(11.1)$ & $\mathrm{BM}(83.3)$ & $52.80 \pm 13.20$ \\
\hline Salbutamol & $9(0)$ & AAS, AC, BF, ES, SAP, SC (22.2) & $\mathrm{KM}(85.4)$ & $41.40 \pm 14.50$ \\
\hline Griseofulvin & $4(1)$ & SS (22.2) & BM, MM, OM (61.1) & $46.30 \pm 7.80$ \\
\hline Calamine lotion & $7(6)$ & $\mathrm{BF}(33.3)$ & $\mathrm{ON}(83.3)$ & $61.60 \pm 9.80$ \\
\hline Nystatin oral & $2(0)$ & AAN, AC, BF, EJ, ON, SAP $(0.0)$ & $\mathrm{AK}, \mathrm{OM}(27.7)$ & $9.70 \pm 6.15$ \\
\hline Lactulose liquid & $6(0)$ & AAS, AC, AW, AKS, BF, ON (0.0) & $\mathrm{KM}(55.5)$ & $13.50 \pm 11.6$ \\
\hline
\end{tabular}

*The number in parenthesis is the number of formulations of the various medicines manufactured locally in Ghana. Foreign manufactu rers accounted for 198 (61.3\%) while local (Ghanaian) manufacturers made up 125 (38.7\%) of the 323 formulations of the 42 children's medicines surveyed.

The two children's antiepileptic drugs in the essential medicines list, phenobarbitone and phenytoin suspensions, had unacceptably very low average availabilities of $4.4 \%$ and $0.4 \%$, respectively. Fourteen (51.8\%) of the 27 districts had no phenobarbitone suspension while twenty five $(92.6 \%)$ had no phenytoin suspension available in the medicine outlets (Table 3 ). Cetirizine syrup was the most available antihistamine medicine $(83.0 \%)$ while albendazole suspension was the best available anthelminthic medicine (90.0\%). Salbutamol syrup, an antiasthmatic drug had an average availability of $41.4 \%$ (range: 22.2-85.4\%) (Table 4). In all, the children's medicine with the highest availability was ferrous sulphate-containing haematinic syrups (95\%), followed by albendazole suspension (90\%) and then paracetamol syrup (88.8\%). Phenytoin suspension had the lowest availability $(0.4 \%)$. Children's medicines available in the Ashanti Region were sourced from manufacturing companies in two
African countries 2 (2.2\%), five Asian countries 44 (47.4\%), eight European countries 46 (49.7\%) and one from North America $1(1.1 \%)$. India had the highest number of foreign manufacturing companies 36 (38.7\%) followed closely by the United Kingdom 33 (35.5\%). A total of 323 formulations (innovator brands and generics) of the 42 children's medicines were identified in the survey.

The number of the formulations produced locally in Ghana was 125 (38.7\%) while those manufactured abroad and imported into the country was 198 (61.3\%). The highest stock-out duration of the medicines surveyed was up to one week (68.40\%), followed by two weeks (14.6\%), then one month (14.0\%) and the least being over one month (3\%). It was observed from the survey that private facilities had the shortest stock-out duration whilst public/government facilities had the longest duration (one month and over). 


\section{DISCUSSION}

In the survey of the availability of medicines for children in Ashanti Region, Ghana, $56.8 \%$ of respondents were males whilst $43.2 \%$ were females. The respondents were the principal personnel who were in-charge or managers of the medicine outlets or facilities surveyed. This suggests that males dominate the retail medicine distribution sector of the healthcare delivery system in the Region. The age group 26-30 years, dominated the sector $(31.4 \%)$ while the age group 60 years and above, formed the lowest $(4.40 \%)$ group of the sector. Personnel who are trained professionals or at least have received some formal training in the handling, dispensing, distribution and/or preparation of medicines, namely: pharmacists, dispensing technologists and medicine counter assistants (MCA's) constituted $63.8 \%$ of the total number of respondents. The rest of the respondents (36.2\%), including health workers such as physician assistants and nurses/midwives were people without any formal training in the handling, dispensing and distribution of medicines. Of the different categories of respondents, the MCA's constituted the highest proportion (30\%). The MCA's are personnel who have received about six months to one year basic training in dispensing of medicines after obtaining the basic SSCE/WASSCE certificate. Their knowledge levels and skills are not adequate to be put in charge of medicine outlets where prescription medicines are dispensed without the proper supervision by pharmacists. Unfortunately, the proportion of pharmacists who were found in charge of medicine outlets during the survey was rather low $(20 \%)$. Thus, the handling, dispensing and distribution of medicines in many facilities in the Ashanti Region were being undertaken by untrained non-professionals. It was ascertained from the survey that pharmacists' presence was high in facilities located in urban areas and was rather low or non-existent in facilities located in rural areas. This trend can adversely affect the distribution and availability of essential medicines as well as the health of the population.

In Ghana and other resource-poor countries, there is lack of age-appropriate pharmaceutical formulations for children. This has led to the pervasive manipulation of adult medicines through tablet splitting and crushing to meet the treatment needs of children. The manipulation of adult medicines for children is known to affect the stability of the resultant product, uptake of the medicine in the child's body and accuracy of dosing of the medicine (IFPMA, 2015). There is therefore the need for the availability of appropriate amounts of children's medicines to meet the specialized needs of children. The average availability of children's medicines across the 27 districts of the Ashanti Region was $41.3 \%$ (range: $26.4-52.0 \%$ ). The level of availability of children's medicines found in the current survey was much lower than the $67 \%$ reported in the survey of Christian health facilities conducted by the Ecumenical Pharmaceutical Network in Ghana (EPN, 2011). Only the Kumasi Metropolis showed an average availability greater than $50 \%$ in the present study. The rather poor average availability of essential children's medicines implies that children in the districts concerned will have little or no access to essential medicines when needed. A minimum of six $(14.3 \%, \mathrm{KM})$ of the children's medicines, omeprazole, tinidazole, furosemide, spironolactone, praziquantel and thiabendazole, and a maximum of seventeen $(40.5 \%, \mathrm{BF})$, namely: lactulose liquid, tinidazole, nystatin oral, dihydroartemisinin-piperaquine, thiabendazole, ciprofloxacin, azithromycin, spironolactone, cefuroxime, praziquantel, ferrous fumarate, phenobarbitone, phenytoin, chlorpheniramine, liquid paraffin, omeprazole and furosemide, were totally unavailable in the districts surveyed. Thus, children in those districts are at risk of death when some of these life-saving medicines are needed for the management and treatment of their diseases.

Results from the survey also showed that six (14.3\%) of the children's essential medicines contained in the STG were nonexistent in the medicine outlets in all the 27 districts in Ashanti Region. These medicines were omeprazole, tinidazole, furosemide and spironolactone suspensions, and praziquantel and thiabendazole syrups. The non-availability of these medicines means that children in the Ashanti Region who may suffer from diseases such as esophageal problems, protozoan infections, congestive heart failure, Schistosoma and worm infections, may not have access to the full range of therapeutic products needed for their effective management or treatment. Many reasons have been assigned by respondents for the non-availability of these medicines in their facilities. These formulations are not very commonly prescribed and are therefore not stocked in the medicine outlets. Also, some of the medicines have modern and more patientacceptable alternatives, such as the use of albendazole in place of thiabendazole for the treatment of worm infections. Thus, albendazole is currently preferred to thiabendazole in therapy. Also, medicines such as omeprazole, furosemide and spironolactone suspensions are mostly prepared extemporaneously by pharmacists in hospitals, hence community pharmacies and other medicine outlets in the community would not stock such medicines in their facilities.

The low percentage availability of children's medicines obtained in the Ashanti Region (41.3\%) is not dissimilar to results obtained from studies conducted in other countries such as India (55.8\%), the Netherlands (48\%), New Zealand (35\%), United Kingdom (59\%), and USA (54\%) (Desai et al., 2012; van RietNales et al., 2011; Chui et al., 2014; Balakrishnan et al., 2006; Balakrishnan et al., 2007). The results of the studies undertaken elsewhere confirms the observation that the low availability of paediatric medicines is not limited to certain regions such as Africa and other developing countries but that it is a world-wide phenomenon (van Riet-Nales et al., 2011).

The principal causes of childhood death are reported to be pneumonia, diarrhea, malaria, neonatal pneumonia and sepsis (Robertson et al., 2009). Childhood pneumonia and diarrhea are responsible for almost $30 \%$ of all child deaths worldwide (Walker et al., 2013), while $22 \%$ of newborn deaths are due to infections such as septicaemia, malaria, pneumonia and diarrhea (Hoppu and SriRanganathan, 2015). The average availability levels of the 
various therapeutic groups of paediatric medicines in the Ashanti Region was generally poor. Artemether-lumefantrine suspension (AL) was the most available of the three artemisinin-based combination therapy (ACT) antimalarials, with an average availability of $72.8 \%$. The two other designated ACTs, artesunateamodiaquine powder for children/paediatric (AA) and dihydroartemisinin-piperaquine powder for suspension (DP) had poor availability levels of $33.5 \%$ and $32.6 \%$, respectively. AL is therefore the most readily available antimalarial in the Ashanti Region for the treatment of uncomplicated malaria in children. There is however the need for an improvement in the availability levels of both AA and DP so that children in the region can have access to the full complement of medicines required for the effective treatment of malaria which is the number one killer of children in Ghana and other malaria endemic areas.

The availability of antibiotics used in the management of various bacterial infections in children ranged from as low as $17 \%$ (ciprofloxacin suspension) to as high as $80.4 \%$ (metronidazole suspension). There is the urgent need to increase the availability levels of antibiotics such as clindamycin, cefuroxime, erythromycin and azithromycin, whose availabilities were below $50 \%$. Amoxicillin, azithromycin, co-amoxiclav and cefuroxime which are indicated for the treatment of pneumonia in children had availabilities of $76.4 \%, 43.8 \%, 50.6 \%$ and $36.0 \%$, respectively. There is therefore the need to increase the availabilities of azithromycin, co-amoxiclav and cefuroxime to enhance access to these important anti-pneumonia medicines. Also, the availabilities of the anti-sepsis medicines clindamycin and flucloxacillin were $18.4 \%$ and $68.7 \%$, respectively. The rather poor availability of clindamycin is a great cause for concern in the fight against sepsis in children. Diarrhea is a major public health problem in Ghana and the children's medicines used in bacterial diarrhea (ciprofloxacin 17.0\%; co-trimoxazole 77.5\%), amoebic diarrhea (metronidazole $80.4 \%$ ), and cholera (erythromycin 43.5\%) had variable availability levels. Zinc supplementation for diarrhea also had an average availability of $58.0 \%$. The stock levels of ciprofloxacin, erythromycin and zinc supplementation in medicine outlets in the Ashanti Region should be increased to boost the fight against diarrheal diseases in children. Other children's medicines with particularly low average availabilities were phenytoin syrup $(0.4 \%)$, ferrous fumarate syrup (0.8\%), phenobarbitone syrup $(4.40 \%)$, nystatin oral $(9.7 \%)$, lactulose liquid (13.5\%), chlorpheniramine syrup (13.0and liquid paraffin (24.0\%). Thus children in the region suffering from conditions such as epilepsy, oro-fungal infections and gastrointestinal and haematological disorders may not have the relevant medicines for use. The study has shown that there is low or poor availability of children's medicines which covers a broad range of therapeutic areas in the Ashanti Region of Ghana. A similar finding was reported in a study undertaken in the Netherlands (van Riet-Nales et al., 2011). Various reasons were advanced by respondents for the rather low availability/non-stocking of some of the children's medicines. Some of the reasons were the high cost of medicines such as ciprofloxacin syrup and clindamycin syrup which could reach their expiry dates without being purchased by clients; lack of funds to purchase relevant children's medicines; lack of availability of selected children's medicines from wholesalers, such as lactulose, folic acid syrup, chlorpheniramine syrup and zinc tablets. Other children's medicines such as clindamycin syrup, ciprofloxacin suspension and phenobarbitone syrup, were not available in some facilities because such drugs being prescription-only medicines are not legalized for sale in chemical shops. Some facility managers were also unaware of the existence of certain children's medicines which they could stock in their medicine outlets. Children's medicines which have low or poor prescribing patterns by doctors, or exhibited seasonality of use also suffered from low availability. Also, children's medicines with ready substitutes/alternatives had low availability, such as the use of cetirizine syrup as a substitute for chlorpheniramine and promethazine syrups.

In several government hospitals griseofulvin tablets are crushed for children instead of using the children's suspension, as the tablets are cheaper. It must however be noted that griseofulvin is not the preferred medication for many fungal skin infections as other agents are more cost-effective and more convenient to the patient. Albendazole suspension had a relatively higher availability than mebendazole suspension due to the multi-dose nature of the latter, against the single dose of the former which was preferred by clients. The rather very poor availability of syrup phenytoin $(0.40 \%)$ may be due to its high price, the low incidence of epilepsy in the region and the availability of phenobarbitone syrup, a cheaper alternative. In general, retail community pharmacies were better stocked with children's medicines than government and faith-based hospitals/clinics. Possible reasons for this trend include the rather inefficient and bureaucratic tender systems employed for the procurement of medicines in government health facilities and the rather low National Health Insurance (NHIS) rates that negatively affects the medicine-stocking capacities of government health facilities. The low availability of children's medicines in government or public sector medicine outlets has been reported elsewhere (Swain et al., 2015). The three best available children's medicines were ferrous sulphate syrup (95\%), albendazole suspension (90\%), and paracetamol syrup (88.8\%). Results from a previous study found the three most available children's medicines in mission health facilities in Ghana to be paracetamol syrup (98\%), amoxicillin syrup (96\%) and co-trimoxazole syrup (95\%) (EPN, 2011). Other children's medicines with high availability levels obtained in the current study were co-trimoxazole syrup (77.5\%), metronidazole suspension (80.4\%), artemeterlumefantrine suspension (72.8\%) and multivitamin syrup (87.6\%). The high availability levels of these children's medicines is a pointer to the types of children's diseases prevalent in the Ashanti Region and Ghana as a whole. These diseases include anaemias, bacterial infections, and malaria and worm infestations. Generally, the percentage availabilities of children's medicines were higher in the urban areas than in rural areas. The possible reasons for this observation are the higher economic activity and purchasing power of residents in urban areas and the closeness or proximity of facilities in urban areas to sources of medicines supply 
(wholesalers) than the rural areas. There were ten districts without pharmacies and/or hospital pharmacies and were found to be the least-endowed districts as far as availability of children's medicines were concerned. These districts were Adansi North (no hospital), Ahafo Ano South (no pharmacy), Amansie Central (no pharmacy), Amansie West (no pharmacy), Atwima Kwanwuma (no hospital), Bosome Freho (no pharmacy and no hospital), Sekyere Afram Plains (no pharmacy, no hospital) and Sekyere Central (no pharmacy). There is therefore the need for private entrepreneurs and the Ghana Health Service to come to the aid of the people in these deprived areas, in order to make essential children's medicines more readily available to save the lives of the children.

Locally manufactured essential children's medicines were found to comprise $125(43 \%)$ of the 323 different formulations of the 42 medicines surveyed, whereas foreign manufactured ones accounted for 198 (57\%) of the formulations. A previous report has shown that $70 \%$ of all the medicines distributed in Ghana are imported (Buabeng et al., 2008). This means that the Ashanti Region and Ghana for that matter, still relies heavily on imported essential children's medicines. This situation is rather unacceptable after almost 60 years of independence. Indian manufactured products imported into the country constituted $38.7 \%$ of all the foreign essential children's medicines followed by the United Kingdom (35.5\%). Essential children's medicines imported from the European Community (EU), constituted $41.10 \%$ of the available children's medicines. The rest came from Pakistan (4.3\%), Senegal (1.0\%), Bangladesh (2.2\%), Austria (1.07\%), and Slovenia (2.2\%), China (1.07\%), Malaysia (1.07\%) and Switzerland (1.07\%). Thus, there were more foreign manufactured medicines $(57 \%)$ than locally manufactured $(43 \%)$ ones. This anomaly could be due to the over-emphasis on manufacturing of adult medicines in Ghana. Also, high taxes on imported raw materials and the generally high cost of production discourages local manufacturing. The duration of stock-outs for commonly stocked children's medicines in the facilities surveyed in the Ashanti Region was mostly up to one week (68.4\%). A significant proportion of the medicines found in this category were from private medicine facilities. It must be noted, however, that for many facilities a high proportion of the children's medicines contained in the STG had never been stocked before.

To improve the availability and enhance access to children's medicines, the following recommendations are made:

- There should be regular revision of the Standard Treatment Guidelines (STG) of Ghana to reflect the changes in disease patterns in the country and therapeutic advances as the current STG (2010) is clearly outdated

- The government of Ghana should aim at establishing hospitals with well-stocked pharmacies in all districts without such facilities

- The Pharmacy Council of Ghana should provide incentives and rebates to pharmacists who establish community and wholesale pharmacies in deprived areas of the country

- Local manufacturing of pharmaceutical products should be encouraged by government and other stakeholders to produce life-saving children's medicines to make them more accessible and affordable

- Bureaucratic bottlenecks at the ports of entry must be removed to streamline and facilitate the fast and easy clearance of imported children's medicines into the country

- Taxes on imported active pharmaceutical ingredients and excipients should be reduced as an incentive for local production of essential children's medicines to increase their availability and affordability

- Local manufacturers should be encouraged to produce life-saving children's medicines which are currently unavailable in the Region, such as omeprazole, tinidazole, furosemide, and spironolactone suspensions and praziquantel syrup

- The Pharmacy Council of Ghana should educate managers of all medicine outlets in the country on the importance of stocking essential children's medicines in their facilities

- Drug and therapeutics committees of all health institutions should ensure the availability, affordability and safety of child-specific medicines in all healthcare facilities.

The main limitation of the study was that chemical shops which constituted the major proportion of facilities surveyed are forbidden by law to stock and dispense prescription medicines. Some of the managers/proprietors of such facilities may therefore be reluctant to declare the availability of prescription-only paediatric medicines they may be holding illegally in their facilities for fear of being reported to the regulatory authorities. Another limitation of the study was the uneven distribution of health centres/clinics, pharmacies and chemical shops in the various districts surveyed. Many of the medicine outlets in the deprived districts had little or no community or hospital pharmacies which affected the availability of children's prescription medicines in such districts.

\section{CONCLUSIONS}

It can be concluded from the study that there is low availability of the 42 children's essential medicines contained in the Standard Treatment Guidelines of Ghana in the Ashanti Region. Moreover, six of the essential children's medicines surveyed were totally unavailable in the whole Region. The low availability of the children's medicines spanned many of the districts and different therapeutic areas. The study has demonstrated the need for policy makers and health administrators to implement policies and initiatives that will lead to improvement in the availability and access of life-saving medicines for children 
to cover all the relevant therapeutic groups, districts and regions of Ghana to improve healthcare delivery.

\section{ACKNOWLEDGEMENTS}

We are grateful to the Ashanti Regional Health Directorate, and the Pharmacy Council Zonal Office, Kumasi, for providing the relevant information for the study.

Our special appreciation and thanks also goes to the medical administrators, superintendent pharmacists, proprietors of licensed chemical shops and respondents in the various districts in the Ashanti Region for their support and co-operation in the conduct of the study.

Financial support and sponsorship: The authors are grateful to the Association of African Universities (AAU) for the award of a Small Grant for Dissertations and Theses to GF.

Conflict of Interests: There are no conflicts of interest.

\section{REFERENCES}

Balakrishnan K, Grieve J, Tordoff J, Norris P, Reith D. Paediatric licensing status and the availability of suitable formulations for new chemical entities approved in the United States between 1998 and 2002. J Clin Pharmacol, 2006; 46: 1038-1043.

Balakrishnan K, Tordoff J, Norris P, Reith D. Establishing a baseline for the monitoring of medicines availability in the UK: 19982002. Br J Clin Pharmacol, 2007; 63: 85-91.

Balasubramaniam R, Beneragama BVSH, Sri Ranganathan S. A national survey of availability of key essential medicines for children in Sri Lanka. Ceylon Med J, 2011; 56(3): 101-107.

Buabeng KO, Duwiejua M, Matowe LK, Smith F, H. Enlund H. Availability and choice of antimalarials at medicine outlets in Ghana: The question of access to effective medicines for malaria control. Clin Pharmacol Ther, 2008; 84(5): 613-619.

Chui J, Tordoff J, Kennedy J, Reith D. Trends in accessibility to medicines for children in New Zealand: 1998-2002. Br J Clin Pharmacol, 2004; 57: 322-327.

Chui J, Tordoff J, Reith D. Changes in availability of paediatric medicines in Australia between 1998 and 2002. Br J Clin Pharmacol, 2004; 59(6): 736-742.

Desai M, Jain K, Shah S, Dikshit RK. Availability of pediatric medicines and their perception among prescribers at a tertiary care teaching hospital. J App Pharm Sci, 2012; 2(8): 171-173.

Ecumenical Pharmaceutical Network. Children's medicines in Ghana - an investigation into availability and factors impacting access, 2011. [ONLINE] Available at: http://apps.who.int/medicinedocs/ documents/s20015en/s20015en.pdf. [Accessed 19 April 2016].

European Medicines Agency, "Paediatric Medicine - Paediatric Regulation", 2015. [ONLINE] Available at: http://www.ema.europa.eu/ ema/index.jsp?curl=pages/regulation/document_listing/document_listing 000068.jsp. [Accessed 14 March 2016].

Finney E. Children's Medicines. A Situational Analysis. A WHO Report, 2011.

Ghana Statistical Service. Population and Housing Census, 2010 summary of report of final results, 2012.
Hoppu K, Sri Ranganathan S. Essential medicines for children. Arch Dis Child, 2015; 100: S38-S42. DOI: 10.1136/archdischild-2013 305705

International Federation of Pharmaceutical Manufacturers \& Associations. Pediatric Medicines, 2015. [ONLINE] Available at: http://www.ifpma.org/quality/pediatric-medicines.html [Accessed 14 March 2016].

International Pharmaceutical Federation (FIP). FIP Statement of Policy - Quality Use of Medicines for Children, Approved by FIP Council in Basel, 2008.

1993.

Ministry of Health, Ghana, Essential Drugs List, $2^{\text {nd }}$ Edition, Edition, 2010

Ministry of Health, Ghana, Standard Treatment Guidelines, $6^{\text {th }}$

Ministry of Health. Health Sector Programme of Work 2007: Independent Review (Draft Report 2008). Ministry of Health, Accra, Ghana, 2006.

Ojoo A. Medicines for children: progress and challenges in the Commonwealth", 2015. [ONLINE] Available at: http://www.commonwealthpharmacy.org/leading_article/medicines-forchildren-progress-and-challenges-in the commonwealth-2/. [Accessed 14 March 2016].

Olski TM, Lampus SF, Gherarducci G, Raymond AS. Three years of paediatric regulation in the European Union. Eur $\mathrm{J}$ Clin Pharmacol, 2011; 67(3): 245-252.

Robertson J, Forte G, Trapsida JM, Hill S. What essential medicines for children are on the shelf? Bull World Health Organ, 2009; 87(3): 231-237.

Swain TR, Rath B, Dehury S, Tarai A, Das P, Samal R, Samal S, Nayak H. Pricing and availability of some essential child specific medicines in Odisha. Indian J Pharmacol, 2015; 47(5): 496-501.

United Nations: The millennium development goals report 2010, New York, United Nations, 2010.

van Riet-Nales DA, de Jager KE, A. F. A. M. Schobben AFAM, Egberts TCG, Rademaker CMA. The availability and age-appropriateness of medicines authorized for children in the Netherlands. $\mathrm{Br} \mathrm{J}$ Clin Pharmacol, 2011; 72(3): 465-473.

Walker CL, Rudan I, Liu L, Nair H, Theodoratou E, Bhutta ZA, O'Brien KL, Campbell H, Black RE. Global burden of childhood pneumonia and diarrhea. Lancet, 2013; 381(9875): 1405-1416.

Wang X, Fang Y, Yang S, Jiang M, Yan K, Wu L, Lv B, Shen Q. Access to paediatric essential medicines: a survey of prices, availability, affordability and price components in Shaanxi Province, China. PLoS ONE, 2014; 9(3): e90365.

\section{How to cite this article:}

Frimpong F, Ofori-Kwakye K. Access to Essential Medicines in Ghana: A Survey of Availability of Children's Medicines in Medicine Outlets in the Ashanti Region. J App Pharm Sci, 2016; 6 (10): 020-028 